\title{
Activity profile of top-class female soccer refereeing in relation to the position of the ball
}

\author{
J. Mallo , S. Veiga, C. López de Subijana, E. Navarro \\ Sports Biomechanics Laboratory, Faculty of Physical Activity and Sport Science, Politechnical University of Madrid, Spain
}

\begin{abstract}
The aim of this study was to describe the activity profile of top-class female soccer referees during competition and to relate it to the position of the ball. Ten matches from the Féderation Internationale de Football Association (FIFA) under-20 female World Championships held in Russia in 2006 were filmed and the kinematical parameters of the female referees $(n=10)$ and the ball were determined using a two-dimensional photogrammetric video system based on direct linear transformation (DLT) algorithms. Total distance covered during a match was $10 \mathrm{~km}$, of which $1.3 \mathrm{~km}$ represented high-intensity activities ( $>13 \mathrm{~km} / \mathrm{h})$. The referees' highest mobility was achicved in the initial $15 \mathrm{~min}$ of the match, covering greater distanee and performing more intense exercise $(P<0.01)$ than in the final 15 -min of the game. Mean distance from the referee to the ball was $19.5 \pm 2.4 \mathrm{~m}$, with no significant diflerences between 15 min match periods. The results of this study show that: (1) the physical demands placed on top-class female relerees are much like those experienced during male moderate-standard refereeing and (2) the referees were able to maintain the distance from the ball throughout the match.
\end{abstract}

Keywords: Analysis; Standard; Exercise; Algorithms

\section{Introduction}

The physical demands of male soccer playing and officiating have been extensively studied over the last decade regarding the activity profile, ${ }^{1,2}$ the physiological response during match-play ${ }^{3,4}$ and the physical capacity of players and referess. ${ }^{1,5-7}$ The number of female practitioners of the sport has notably increased during the recent years and, to date, over 40 million of women are estimated to play the game at different competitive standards. Despite this popularity of the sport, little is known about the physical requirements experienced by female players during the game. In recent studies, Krustrup et al. ${ }^{8}$ and Mohr et al. ${ }^{9}$ have revealed that elite female soccer players from the best Danish league covered approximately $9-11 \mathrm{~km}$ during a match, with $10-15 \%$ of this distance covered at high-intensities (>15 km/h).

The physical performance of referees during a soccer match can be affected by different factors such as the physical capacity, ${ }^{1,10}$ the development of fatiguc, ${ }^{3.7}$ the standard of the competition ${ }^{11,12}$ or the amount of high-intensity activities performed by the players. ${ }^{13}$ The Fédération Internationale de Football Association (FIFA) determines that international female tournaments must be officiated by female referes. To our knowledge, there are no studies that have attempted to examine the movement patterns of referees during these soccer games, leaving uncertainty to what extent would female games affect the physical demands placed on the referees. As female players produce less high-intensity activities during competitive matches than male players, ${ }^{2,8,9}$ it would be expected that the physical strain of female refereeing would be lower than that experienced during male soccer matches.

At the same time of describing the movement activity of the referee, it seems essential to relate these displacements to the position of the ball, as the referee needs to follow the play closely in order to apply the Laws of the Game. In a recent study, Mallo et al. ${ }^{14}$ reported a significant relationship between the total distance covered $(r=0.77)$ and the amount of high-intensity activities $(r=0.67)$ performed by the referec and the distance covered by the ball within the same match. It appears crucial to examine the distance between the referee and the ball throughout the match as it could be used as an 
additional parameter to objectively evaluate the physical and technical performance of the officials, representing the ability of the referee to keep up with the play. Thus, the aim of this study was to describe the activity profile of top-class female soccer refereeing, taking into consideration the position of the ball.

\section{Methods}

The participants of this study were 10 top-class female soccer referees. The referee represents the maximum authority in the soccer field and during a match can move in any direction on the ground, safeguarding the respect to the Laws of the Game. Their mean ( \pm S.D.) age, height and body mass were $35.3 \pm 4.3$ years, $168.4 \pm 3.9 \mathrm{~cm}$ and $62.5 \pm 6.4 \mathrm{~kg}$, respectively. All of the subjects had no less than 6 years of experience at the international level and all the measurements were carried out in a 3 -week period during the FIFA female under-20 World Championships held in Russia (August-September 2006).

Ten matches were filmed using three fixed digital video cameras and analysed with a two-dimensional photogrammetric video system. ${ }^{7,14-16}$ The vertical projection of the referees' center of mass was digitized in the screen every second throughout the match. Additionally, the position of the ball was also indicated in the screen when it was on the ground, rejecting all the frames where the ball was played in the air or where it could not be seen properly. In these cases (less than $30 \%$ of total time), the starting and finishing position of the ball was indicated in the screen to calculate the horizontal distance between both positions. The calibration system for each of the cameras was digitized and 2D-DLT (direct linear transformation)-based algorithms ${ }^{17}$ were used for the calculation of the real positions in the field. These $x, y$ positions were smoothed using quintic spline functions with the Cross Generalised Validation procedure as a method for evaluating the adjusting factor. ${ }^{18}$

The displacement and speed were calculated from the spline polynomial functions. The movements of the referees were classified into the following categories ${ }^{7,14-16}$; (a) standing still, <3.6 km/h; (b) walking, 3.61-7.20 km/h; (c) jogging, $7.21-13 \mathrm{~km} / \mathrm{h}$; (d) cruising, 13.01-18 km/h; (e) high-speed running, $>18 \mathrm{~km} / \mathrm{h}$. The movements performed at speeds greater than $13 \mathrm{~km} / \mathrm{h}$ were entitled as high-intensity activities. Performance throughout the match was computed in 5, 15 and 45 min periods. All the incidents (foul play, hand ball, etc.) indicated during the match were captured and digitized at a frame rate of $25 \mathrm{~Hz}$. The position of the referee and where the incident was indicated were digitized and the distance between both points calculated. At the same time, the distance from the referee to the ball, when it was on the ground, was calculated throughout the match.

Previous research ${ }^{7}$ has determined the validity and reliability of this methodology for match analysis. The root mean square error when reconstructing the distance between two points was less than $2 \%$. The inter- and intra-reliability tests did not reveal any significant differences $(P<0.05)$ between observations, with total differences in the measurements consistently less than $1 \%$.

All the results are presented as mean \pm S.D. Differences in match activities between both halves of the game were determined using a paired $t$-test. Differences in distance covered, high-intensity activities and distance from the ball over consecutive 15 -min periods of play were determined using repeated measures analysis of variance (ANOVA). An ANOVA test was also used to evaluate the variations in the movement activities performed on both halves. When a significant interaction was detected, data were subsequently analysed using a Newman-Keuls post hoc test. Significance was accepted when $P<0.05$.

\section{Results}

Total distance covered during a match was $10,032 \pm 300 \mathrm{~m}$, with a decrease $(P<0.01)$ from $5176 \pm 201 \mathrm{~m}$ in the first half to $4856 \pm 197 \mathrm{~m}$ in the second half. During the first 15 min of the match the referees covered the greatest distance, $1840 \pm 137 \mathrm{~m}$; this value was higher than that reached in the initial $15 \mathrm{~min}(P<0.05)$ and final $30 \mathrm{~min}(P<0.01)$ of the second half.

The distance covered at different activity categories are shown in Table 1. The referees stood still for $38.1 \pm 3.5 \%$ and walked for $25.7 \pm 3.7 \%$ of the total time. Medium-intensity activities (jogging) accounted for $21.1 \pm 1.7 \%$, while the remaining time was spent cruising $(9.5 \pm 1.1 \%)$ and running at high-speeds $(5.6 \pm 0.9 \%)$.

Time spent performing high-intensity activities during a match was $815 \pm 87 \mathrm{~s}$, with 110 statistically significant difference $(P=0.09)$ between the first and second halves: $431 \pm 71 \mathrm{~s}$ vs. $384 \pm 41 \mathrm{~s}$, respectively. The referees carried out more high-intensity activities in the first 15min $(161 \pm 15 \mathrm{~s})$ than between minutes 46-60 (134 \pm 27 ; $P<0.05)$ and $61-90(128 \pm 21$ and $123 \pm 28$, respectively; $P<0.01)$. After the 5 -min period of each half where the referees performed the most high-intensity activities $(63 \pm 8 \mathrm{~s})$, during the following 5-min period, time spent performing intense exercise was reduced $33 \%(42 \pm 11 \mathrm{~s} ; P<0.001)$. This value was not significantly different from the 5 -min mean of the match $(45 \pm 7 \mathrm{~s})$.

\section{Distance from the ball}

Distance covered by the ball during the match was $17,987 \pm 2378 \mathrm{~m}$. Mean distance from the referee to the ball throughout the match was $19.5 \pm 2.4 \mathrm{~m}$, with no differences between the first and the second half: $19.3 \pm 2.3 \mathrm{~m}$ vs. 19.6 $2.5 \mathrm{~m}$, respectively. As it can be seen in Fig. 1, the referees were closer to the ball in the first $15 \mathrm{~min}$ of the match $(18.7 \pm 2.5 \mathrm{~m})$, although no differences were 
Table l

Distance (m) covered by different match activities (mean \pm S.D.).

\begin{tabular}{|c|c|c|c|}
\hline & First half & Second half & Overall \\
\hline Standing still & $952 \pm 202$ & $945 \pm 203$ & $1897 \pm 315$ \\
\hline Walking & $1107 \pm 133$ & $1070 \pm 131$ & $2176 \pm 244$ \\
\hline Jogging & $1446 \pm 181$ & $1375 \pm 169$ & $2821 \pm 260$ \\
\hline Cruising & $901 \pm 93$ & $846 \pm 112$ & $1747 \pm 179$ \\
\hline High-speed running & $770 \pm 189$ & $620 \pm 163$ & $1390 \pm 171$ \\
\hline Total & $5176 \pm 20 \mathrm{l}$ & $4856 \pm 197^{\mathrm{a}}$ & $10,032 \pm 300$ \\
\hline
\end{tabular}

a Significant difference $(P<0.01)$ between the first and secend halves.

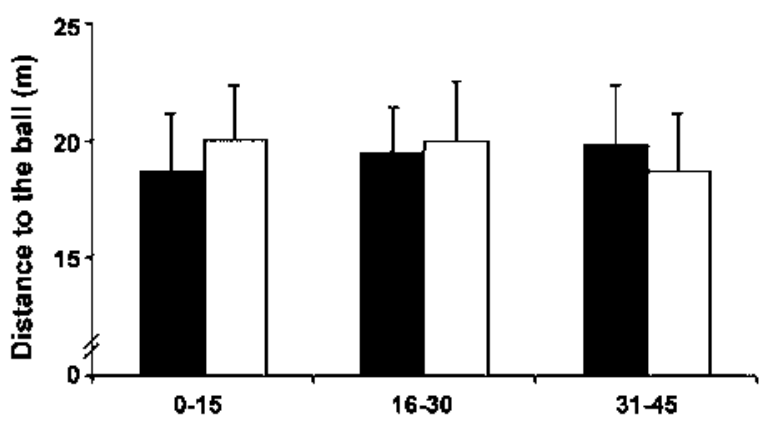

Fig. 1. Distance $(\mathrm{m})$ from the referee to the ball for 15 -min periods during the first (dark bars) and sccond (light bars) halves of the match (nean \pm S.D.).

detected between $15 \mathrm{~min}$ periods. The mean distance from the incidents $(n=174)$ was $17.9 \pm 7.2 \mathrm{~m}$, with no differences between halves.

\section{Discussion}

The results of this study show that the movement patterns of top-class female soccer referees are similar to those described during male moderate-standard refereeing. Mean distance covered by female referees during a match was $10 \mathrm{~km}$, of which $1.3 \mathrm{~km}$ represented high-intensity activitics. The referees experienced the highest mobility in the initial $15 \mathrm{~min}$ of the match, when they covered more distance, performed more high-intensity activities and were nearer to the ball than in the remaining $15 \mathrm{~min}$ periods. The decline of activity observed during the second half of the matches could be related to a lower tempo in the play imposed by the players, as the referees were able to maintain the distance at which they follow the play throughout the entire match.

To our knowledge, this is the first study that provides information on the kinematical demands placed on female soccer referees. The distance covered by the referees ranged from 9.6 to $10.5 \mathrm{~km}$, with a mean value of $10 \mathrm{~km}$, which is very similar than that previously reported for female 8,9 and modcrate male ${ }^{2}$ soceer players and when referecing male soceer competitive games. ${ }^{1,14}$ The time-motion analysis revealed that referees performed low-intensity activities (standing and walking) for $64 \%$ of total time, medium-intensity activitics for $21 \%$ and high-intensity activities for the remaining $15 \%$. Krustrup et al. ${ }^{8}$ showed that elite female Danish players stood and walked for $60 \%$ of the tolal match time, which could suggest that the volume of low-intensity activities remains fairly constant both for female referees and players. Nevertheless, it is nowadays unanimously accepted that the amount of high-intensity activities is the best indicator of the demanding periods of the match and is competitionstandard dependent. ${ }^{1,2,9,11,12,14}$ To ascertain the inter-gender differences in top-class refereeing we compared the actual activity profile of the female referees with that from top-class male referees $(n=9)$ presented in a previous study, ${ }^{14}$ The results of the 2 (gender: male; female referees) $\times 5$ (activity category) repeated measures ANOVA showed an effect for activity category $\left(F_{4,68}=53.39 ; P<0.001\right)$ and a gender $x$ activity catcgory interaction $\left(F_{4,68}=7.26 ; P<0.01\right)$. Interestingly, the male top-class referecs that took part in the FIFA Confederations Cup 2005 ran at high-speed $38 \%$ further ( $1920 \pm 399 \mathrm{~m}$ vs. $1390 \pm 171 \mathrm{~m} ; P<0.01$ ) than the females' referees from the under- 20 World Cup. The inferior values of aerobic power $\left(\mathrm{VO}_{2 \max }\right)$ possessed by female players ${ }^{19,20}$ in comparison to male players ${ }^{5,21}$ could explain the lower pace of female games, as it has been observed by Krustrup et al. ${ }^{8}$ a meaningful relationship between the individual $\mathrm{VO}_{2 \max }$ values and the amount of high-intensity running performed by female players during competitive matches. It should be noted that in the current study the players were aged under 20 years, which could have also influenced this variation in the volume of intense exercise.

The distance covered $(P<0.01)$ and the volume of highintensity activitics $(P=0.09)$ performed by the referees decreased in the sccond $45 \mathrm{~min}$ of the game in relation to pre-halftime values. Specifically, the referees' highest activity was achieved in the initial $15 \mathrm{~min}$ period of the game, when they covered more distance and performed more intense exercise than in any other $15 \mathrm{~min}$ period after halftime. This inter-period decline of physical performance has been also detected in other studies carried out with referees ${ }^{3,7}$ and players. ${ }^{2}$ It appears crucial to determine if this underperformance was due to an impairment in the physical capacity of the officials or if it was related to a lower tempo in the game imposed by the players. In order to determine the possible effect of fatigue in the technical aspects of referecing, we examined the distance from the referec to the ball throughout the match. Although the referees were closer to the place where the ball was played in the initial 15 min period of the match (Fig. 1) we could not detect any difference with any 
other 15 min period. This data would suggest that female referees spared their physical capacity in order to fulfil the demands of the match and were able to keep in distance from the ball in the final stages of the game. However, complementary studies that simultaneously determine the time-motion analysis of players, officials and the ball should be carried out to establish the relationships between all of them.

In summary, the overall demands experienced by top-class female referees during competition are much like the requirements of moderate-standard male refereeing. The standard of the competition rises the physical strain and referees need to perform more maximal-intensity activities to follow the play. The lowered activity in second half of the game seemed to be related to a decline in the pace imposed by the players as the referees were able to keep constant the distance from the ball.

\section{Practical implications}

- Specific training plans for female referees should be prescribed based on the physical demands experienced during competitive games.

- Intermittent exercise, with frequent maximal-intensity episodes (sprints), must be the basis of these physical fitness training plans.

- The distance from the referee to the ball throughout the match represents the ability to keep up with the pace of the game. Top-class female referees seem to be at least as fit as elite under- 20 female players because they did complementary not fall behind the play.

\section{Acknowledgments}

This study was supported by the Refereeing Department of the Fédération Internationale de Football Association. Furthermore, the cooperation of Jose María Garcia-Aranda is acknowledged. We would also like to thank FIFA's Medical Assessment and Research Center (F-MARC) for their financial support in this project.

\section{References}

1. Krustrup P, Bangsbo J. Physiological demands of top-class soccer refeteeing in relation to physical capacity: effect of intense intermittent exercise training. S Sports Sci 2001;19:881-91.

2. Mohr M, Kiustiup P, Bangsbo J. Match performance of high-standard soccer players with special teference to development of fatigne. J Sports Sci $2003 ; \mathbf{2 1} ; 519-28$
3. D'Ottavio S. Castagna C. Physiological load imposed on elite soccer referees during actual match play. I Sports Med Phys Fitness 2001;41:27-32.

4. Helsen WF, Bultynck JB. Physical and perceptual-cognitive demands of top-class refereeing in association football. J Sports Sci 2004;22: 179-89.

5. Casajus JA. Seasonal variations in fitness variables in professional soccet players. J Sports Med Phys Fitness 2001;41:463-9.

6. Castagna C, Abt G, D'Ottavio S. Relation between fitness tests and match performance in elite Italian soccer referees. J Strength Cond Res 2002;16:231-5.

7. Mallo J, Navarro E, García-Aranda JM, Gilis B, Helsen W. Activity profile of top-class soccer referees in relation to performance in selected physical tests. J Sports Sci 2007;25:805-13.

8. Kiustiup P, Mohr M, Ellingsgaard H, Bangsto J. Physical demands during an elite female soccer game: inportance of training status. Med Sci Sports Exerc 2005;37:1242-8.

9. Mohr M, Krustrup P. Andersson H, Kitkendall D, Bangsbo J. Match activities of elite women soccer players at different performance levels. J Strength Cond Res 2008;22:341-9.

10. Weston M. Helsen WF, Mac Mahon C., Kirkendall D. The impact of specific high intensity training sessions upon football tefetees' fitness levels. Am I Sports Med 2004;32S:54-61.

11. Castagna C, Abt G, D'Ottavio S. Activity profile of internationallevel soccer referees during competitive matches. J Strength Cond Res 2004;18:486-90

12. Weston M, Bitd S, Helsen W, Nevill A, Castagna C. The effect of match standard and referee experience on the objective and subjective mach workload of English Premier League referees. J Sci Med Sport 2006;9:256-62.

13. Weston M, Castagna C., Impellizzeri FM, Rampinini E. Abt G. Analysis of physical match performance in English Premier League soccer referees with particular reference to first half and player work rates. $J$ Sci Med Sport 2007;10:390-7.

14. Mallo J, Navarro E, García-Aranda JM. Helsen W. Activity profile of top-class association football referees in relation to fitness-test performance and match standard. S Sports Sci 2010;13:129-32.

15. Mallo J, Navarro E, García-Aranda JM. Gilis B, Helsen W. Analysis of the kinematical demands imposed on top-class assistant teferees during competitive soccet matches. I Strength Cond Res $2008 ; 22 ; 235-12$.

16. Mallo J. Navarro E, García-Aranda JM. Helsen W. Physical demands of top-class soccer assistant refereeing during high-standard matches. Itt J Sports Med 2009;30:331-6.

17. Abdel-Aziz YI, Karara HM. Ditect linear transformation from comparator coordinates into space coordinates in close range photogrammetry. In: The American Society of Photogramnetry (ed.). Proceedings of the Symposium on close range photogrammetry. Falls Chutch; 1971. pp. 1-18.

18. Woltring HJ. On optimal smoothing and derivate estimation from noisy displacement data in bionechanics. Human Mov Sci 1985;4:229 45.

19. Jensen $\mathrm{K}$, Larsson B. Variations in physical capacity among the Danish national soccer team for women duting a period of supplementary training. J Sports Sci 1992;10:144-5.

20. Helgerud J, Hoff J, Wisloff U. Differences in strength and endurance between male and female soccer players. J Sports $S c i 1999 ; 17: 813$.

21. Wisloff U, Helgerud J. Hoff J. Strength and endurance of elite soccer players. Med Sci Sports Exerc 1998;30:462-7. 